\title{
First observations of the midlatitude evening anomaly using Super Dual Auroral Radar Network (SuperDARN) radars
}

\author{
S. de Larquier, ${ }^{1}$ J. M. Ruohoniemi, ${ }^{1}$ J. B. H. Baker, ${ }^{1}$ N. Ravindran Varrier, ${ }^{1}$ \\ and M. Lester ${ }^{2}$ \\ Received 27 April 2011; revised 3 July 2011; accepted 5 August 2011; published 27 October 2011.
}

[1] Under geomagnetically quiet conditions, the daytime midlatitude ionosphere is mainly influenced by solar radiation: typically, electron densities in the ionosphere peak around solar noon. Previous observations from the Millstone Hill incoherent scatter radar (ISR) have evidenced the presence of evening electron densities higher than daytime densities during the summer. The recent development of midlatitude Super Dual Auroral Radar Network (SuperDARN) radars over North America and Japan has revealed an evening enhancement in ground backscatter during the summer. SuperDARN observations are compared to data from the Millstone Hill ISR, confirming a direct relation between the observed evening enhancements in electron densities and ground backscatter. Statistics over a year of data from the Blackstone radar show that the enhancement occurs during sunset for a few hours from April to September. The evening enhancement observed by both SuperDARN and the Millstone Hill ISR is shown to be related to recent satellite observations reporting an enhancement in electron densities over a wide range of longitudes in the Northern Hemisphere midlatitude sector during summer time. Finally, global results from the International Reference Ionosphere (IRI) and the horizontal wind model (HWM07) are presented in relation with previously published experimental results and proposed mechanisms of the evening enhancement, namely, thermospheric horizontal winds and geomagnetic field configuration. It is shown that the IRI captures the features of the evening enhancement as observed by SuperDARN radars and satellites.

Citation: de Larquier, S., J. M. Ruohoniemi, J. B. H. Baker, N. Ravindran Varrier, and M. Lester (2011), First observations of the midlatitude evening anomaly using Super Dual Auroral Radar Network (SuperDARN) radars, J. Geophys. Res., 116, A10321, doi:10.1029/2011JA016787.

\section{Introduction}

[2] Under geomagnetically quiet conditions, the daytime midlatitude ionosphere is mainly influenced by solar radiation, tides, gravity waves and thermospheric neutral winds. Typically, electron densities in the ionosphere build up at sunrise through photoionization, maximize around solar noon, and decrease through sunset as photoionization becomes weaker than recombination. Seasonal and geographical variations apply to this simple model of the ionosphere, but any deviation of the daytime electron density variation from the Sun exposure variation is usually considered an anomaly [e.g., Schunk and Nagy, 2009, chapter 11].

[3] Previous work by Evans [1965] presented incoherent scatter radar (ISR) observations of an enhancement in ionospheric electron densities occurring in the summer time

\footnotetext{
${ }^{1}$ SuperDARN HF Radar Group, Virginia Polytechnic Institute and State University, Blacksburg, Virginia, USA.

${ }^{2}$ Department of Physics and Astronomy, University of Leicester, Leicester, UK.

Copyright 2011 by the American Geophysical Union. 0148-0227/11/2011JA016787
}

around 20:00 LT over Millstone Hill, Massachusetts. Evans [1965] showed that soon after solar noon, the $F$ layer density peak starts moving up as recombination happens faster at lower altitudes and electron densities are reduced, but around 16:00 LT the density peak stops recessing and electron densities reach higher values than at solar noon. Evans [1965] attributed this enhancement to the thermal contraction of the topside ionosphere. Eccles and Burge [1973] further investigated the summer evening enhancement in electron density described by Evans [1965]. Modeling results from Eccles and Burge [1973] suggested that the thermal contraction of the topside ionosphere has very little effect on the evening enhancement observed in the $F$ region, but equatorward thermospheric winds seem to be important. Because of the southward inclination of the magnetic field lines, equatorward directed meridional neutral winds can contribute to pushing the lower layers of the ionosphere up the field lines to higher altitude where recombination is slower, which may account for longer lived and higher electron densities in the evening $F$ region. Lei et al. [2005], using all available data from the Millstone Hill ISR, also noticed that the evening enhancement was 


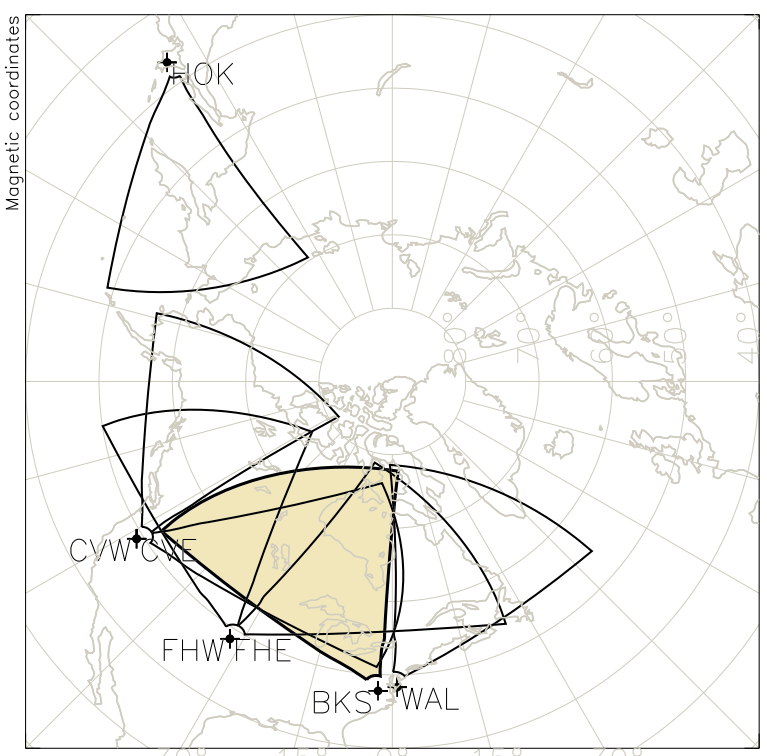

Figure 1. SuperDARN midlatitude radars showing Hokkaido (HOK), Christmas Valley East and West (CVE and CVW), Fort Hays East and West (FHE and FHW), Blackstone (BKS), and Wallops (WAL). Blackstone radar is represented by the shaded field of view. Two more pairs of radars are projected to be built in the Aleutian Islands and the Azores.

strongly dependent on solar activity: the evening enhancement for solar maximum appears much weaker than for solar minimum.

[4] The recent development of midlatitude Super Dual Auroral Radar Network (SuperDARN) radars shown in
Figure 1 has revealed a similar anomaly in the highfrequency (HF) propagation pattern. The SuperDARN HF radars have been successfully used to study a wide range of problems in high-latitude ionospheric electrodynamics [Chisham et al., 2007]. Most studies are based on HF signals backscattering from ionospheric irregularities that develop along geomagnetic field lines [e.g., Ruohoniemi and Baker, 1998]. The strong refraction of HF signals $(8-18 \mathrm{MHz})$ in the ionosphere allows the backscattering conditions to be satisfied over an extended range interval, sometimes exceeding $3000 \mathrm{~km}$. Figure 2 illustrates typical daytime (Figure 2a) and nighttime (Figure $2 \mathrm{~b}$ ) propagation paths for HF signals in the quiet midlatitude ionosphere: it can be seen that during nighttime, the rays tend to propagate through a larger extent of the ionosphere and are consequently more likely to encounter ionospheric irregularities or to be attenuated before ground backscatter reaches the radar. The recent and still ongoing development of midlatitude radars over North America and Japan has extended the coverage of SuperDARN (see Figure 1). Midlatitude ionospheric conditions being generally less active, during the daytime the predominant mode of backscatter involves reflection from the ground after the HF signals are redirected downward by refraction. This feature of HF propagation is used in overthe-horizon HF communication and radar surveillance [e.g., Hughes et al., 2002]. Terrain geometry and composition usually result in part of the energy being scattered back to the radar, where it is identified as ground scatter due to very low velocities and spectral width [e.g., Blanchard et al., 2009]. According to HF propagation theory, the reflected rays are focused in the vicinity of the skip zone boundary defined as the closest distance to the source where rays can reach the ground [e.g., Budden, 1966, p. 183-184]. See Figure 2a for an illustration of the skip focusing. The position and intensity of the ground scatter skip focusing can be used to retrieve

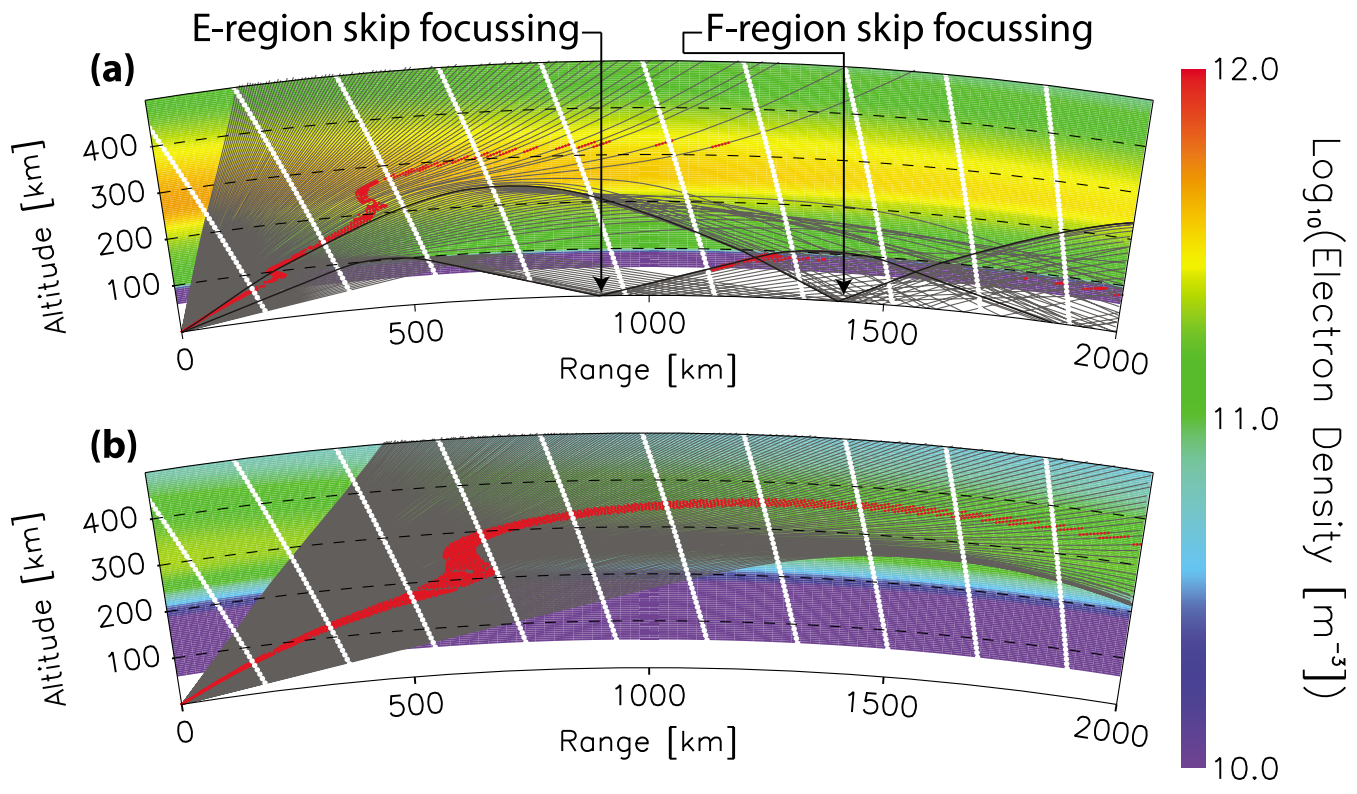

Figure 2. Typical (a) daytime and (b) nighttime HF ray propagation paths in the ionosphere obtained using ray tracing coupled with an ionospheric specification provided by the International Reference Ionosphere (IRI). $E$ and $F$ region skip focusing are emphasized. The red highlighted areas represent regions of good magnetic aspect condition for reflection by field-aligned ionospheric irregularities. 


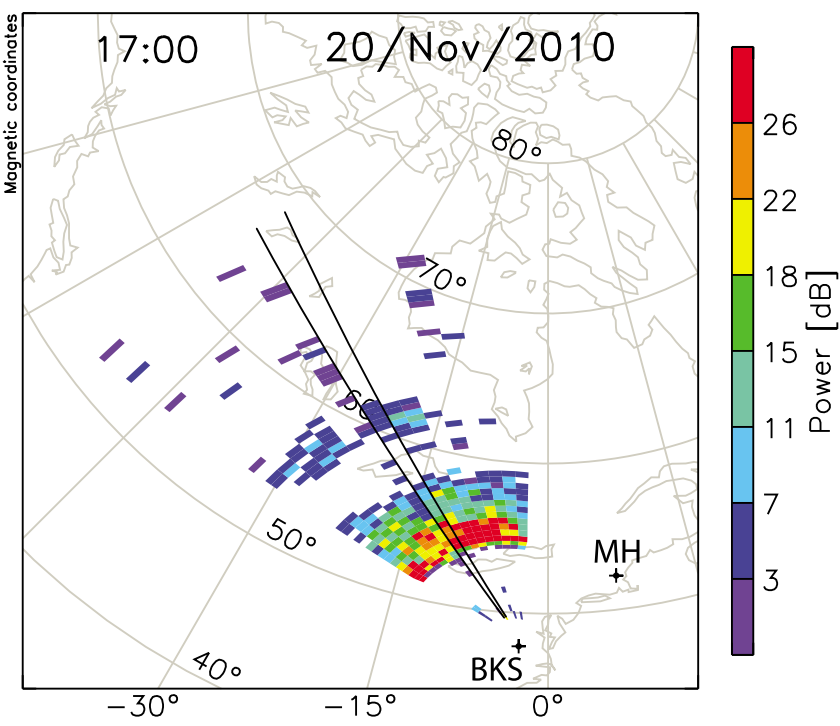

Figure 3. Single 16-beam scan from the Blackstone (BKS) radar illustrating the beam considered for all subsequent range-time analysis of SuperDARN data presented in this paper. Also represented is the position of the Millstone Hill $(\mathrm{MH})$ incoherent scatter radar (ISR).

information on the structure and evolution of the ionosphere [e.g., Hughes et al., 2002]. Figure 3 shows an example of the position of $F$ region skip focusing (red band of scatter) in the Blackstone radar field of view.

[5] While SuperDARN ground scatter has previously been used to study ionospheric dynamics such as traveling ionospheric disturbances or ULF waves [e.g., Samson et al., 1989; Bristow et al., 1996; Ponomarenko et al., 2005], its potential for monitoring long-term seasonal variations of the ionosphere remains largely unexploited [Milan et al., 1997; Norman and Dyson, 2006]. Recent work by Ponomarenko et al. [2010] has demonstrated that seasonal and diurnal changes in the polar cap ionosphere modulates the occurrence rate and spatial coverage of ground scatter. A proper understanding of the occurrence and evolution of ground scatter at midlatitudes is required to retrieve accurate information on the state of the ionosphere, and can be used to test the accuracy of empirical models.

[6] The expected evolution of daytime ground scatter on a geomagnetically quiet day $(K p \leq 2$ and $|D s t| \leq 5 \mathrm{nT})$ can be described as follows (see Figure $4 \mathrm{a}$ for illustration). When the Sun rises, photoionization begins, rapidly increasing the electron densities in the ionosphere [e.g., Kelley, 2009, chapter 5], thus increasing the refractive index, resulting in an increasing number of HF rays being bent to the ground. The HF radar detects ground scatter which moves nearer in range as ionospheric plasma densities build up and the $F$ region peak density altitude is lowered. This process peaks around solar noon when the electron density is at its maximum. When the Sun sets, photoionization nearly stops and recombination of electrons and ions dominates, reducing the plasma density and resulting in a decreasing number of rays being bent to the ground. The ground scatter moves outward in range and eventually vanishes as ionospheric plasma densities fall below the levels required to provide the refraction needed to generate ground scatter. The expected diurnal variation in the range-time format (Figure 4a) is $U$ shaped and nearly symmetrical about a range minimum near solar noon.

[7] In this study we report that during geomagnetically quiet summer days, the daily ground scatter distribution observed at midlatitude SuperDARN radars does not follow the expected diurnal pattern. As can be seen in Figure 4b, an enhancement in ground scatter occurs in the evening around sunset. The ground scatter activity then in fact exceeds the activity observed around solar noon. One of the results of the prolonged ground scatter after sunset is to provide an extended ability to monitor ionospheric dynamics via ground scatter in the evening sector.

[8] Data from the Blackstone HF radar in Virginia $\left(37.10^{\circ} \mathrm{N}\right.$, $282.05^{\circ} \mathrm{E}$ ) collected over the first two years of operation provides the basis of the present work. SuperDARN observations in conjunction with ray tracing model results are compared to previously published data from the Millstone Hill ISR $\left(42.6^{\circ} \mathrm{N}, 288.5^{\circ} \mathrm{E}\right)$ [Evans, 1965; Eccles and Burge, 1973], and to CHAMP satellite observations reported by Liu et al. [2010].

[9] This body of work was motivated by the identification of a peculiar and recurring feature in midlatitude SuperDARN observations: an unexpected enhancement in ground backscatter around sunset. The relation between this feature and the previously reported summer evening anomaly (SEA) will be demonstrated here. On the basis of this relation, we then provide the first comparison with global empirical models such as the International Reference Ionosphere (IRI) and the horizontal wind model (HWM).

\section{Data Sets and Analysis Methods}

[10] The Blackstone radar $\left(37.10^{\circ} \mathrm{N}, 282.05^{\circ} \mathrm{E}\right.$, shaded in Figure 1) has been operating since February 2008. Its field of view provides good coverage of the midlatitude sector over central North America. The ongoing extension of the SuperDARN midlatitude chain under the NSF Mid-Sized Infrastructures (MSI) program will provide wider coverage in the future. As daily distribution of ground scatter does not present a strong azimuthal dependence, data from beam 7 of the Blackstone radar (center beam) will be used in the following analysis (Figure 3). This section provides a general description of standard SuperDARN data presentation format; the figures introduced here will be described in greater detail in section 3. Observations from the Blackstone SuperDARN radar are presented on a range-time plot: data from the center beam of Blackstone are collected with a time resolution of $1 \mathrm{~min}$ (see Figure 3 for a representation of Blackstone's beams), and the returned signal is binned into $45 \mathrm{~km}$ long range gates (beginning at $180 \mathrm{~km}$ range), resulting in the representation presented in Figure 4. The daytime ground scatter is identified by low velocities and small spectral width and usually manifests as a quasicontinuous block in the range-time domain lasting from sunrise to sunset, as can be seen in Figure 4a.

[11] The location of the Millstone Hill ISR with respect to the Blackstone radar shown in Figure 3 allows for effective comparison of Blackstone data with Millstone Hill observations, thus providing a different perspective of ionospheric parameters such as electron density. The 

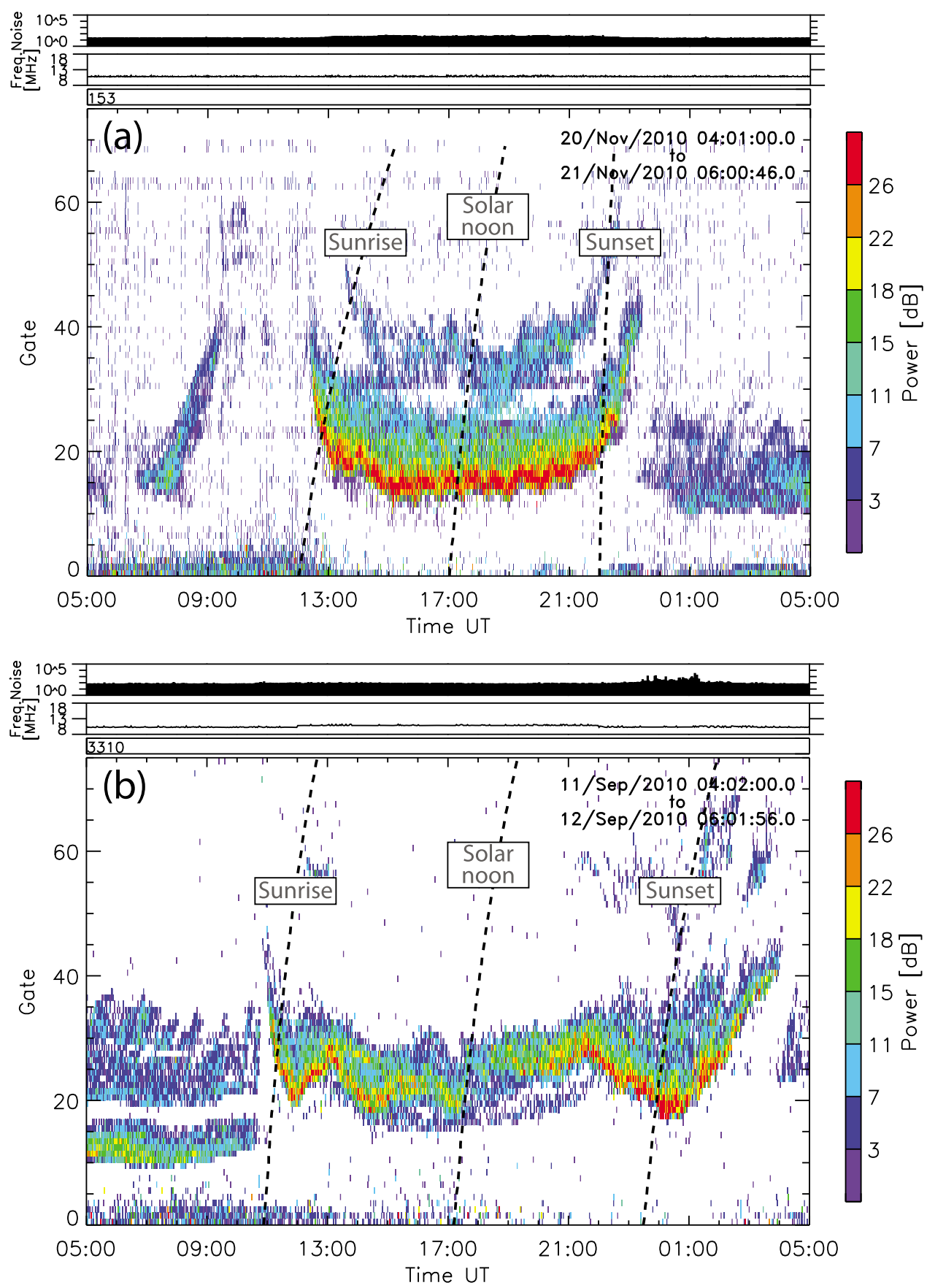

Figure 4. SuperDARN observations from Blackstone radar site for (a) a typical magnetically quiet winter day and (b) a typical magnetically quiet fall day. In Figure 4a the ground scatter occurs between sunrise and sunset, whereas in Figure $4 \mathrm{~b}$, ground scatter signatures extend $4 \mathrm{~h}$ after sunset. Outside of these limits, the returned signal is from subauroral ionospheric irregularities in these particular cases. Sunrise, solar noon, and sunset times are computed in each range cell of beam 7 of the Blackstone radar field of view.

Madrigal database was used to provide ISR data from the Millstone Hill observatory, as can be seen in Figure 5.

[12] To provide a broader seasonal view of ground scatter daily distribution, we conduct a statistical study for specific months of a given year. We compute the mean ground scatter power for a given month in each range gate of beam 7 over time intervals of 30 min for each day of the given month. The power distribution for each day is then summed over the month and normalized by the maximum summed power. This method yields the statistical daily ground scatter distribution and relative intensity. The ground scatter flag provided in SuperDARN data files (based on low velocities and small spectral widths) is used to identify ground scatter echoes as a first-order approximation: improved algorithms have recently been developed for ground scatter identification [Ribeiro et al., 2011], which could potentially refine 

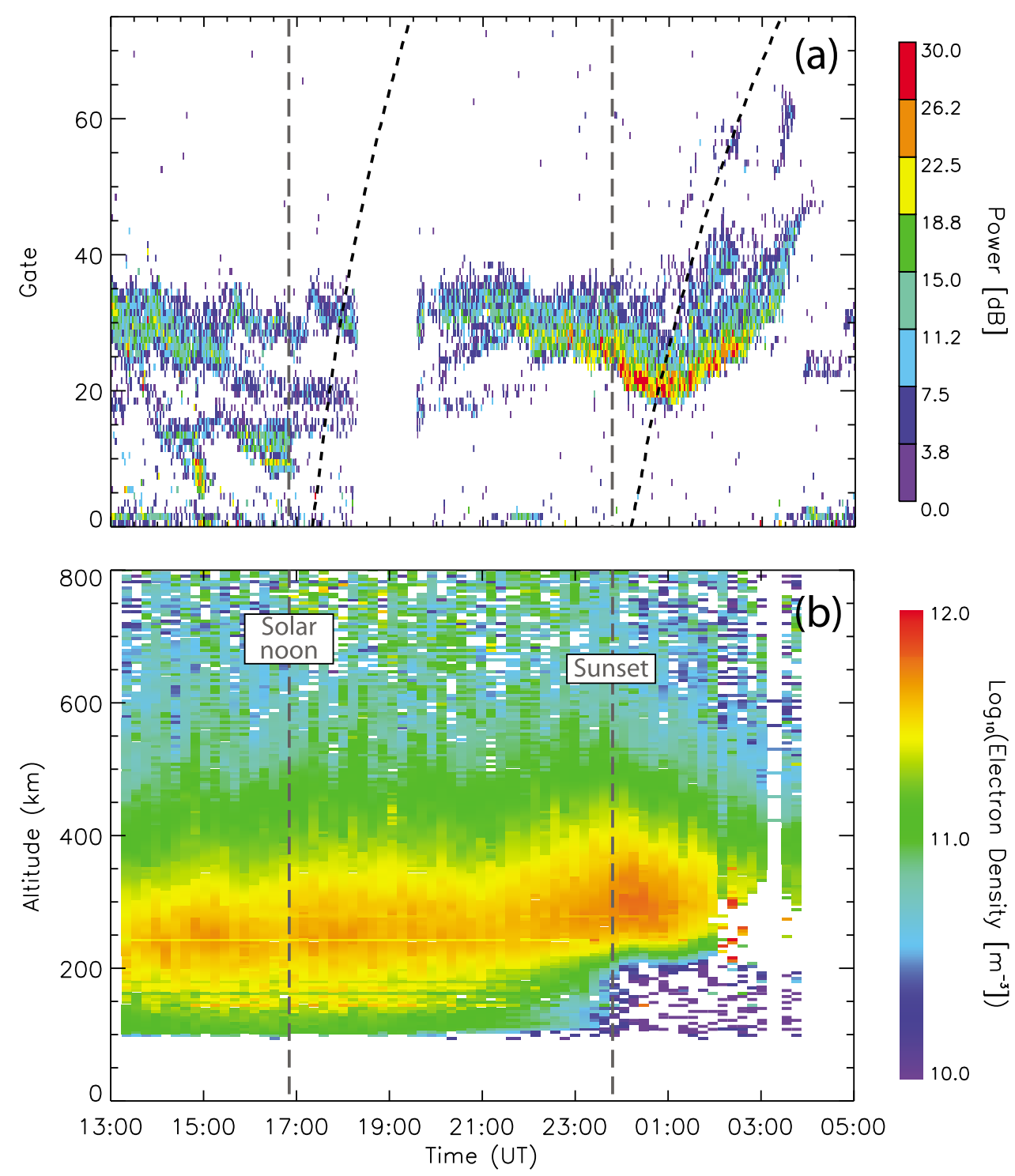

Figure 5. (a) SuperDARN observations from Blackstone beam 7 and (b) the Millstone Hill ISR on 13 August 2010. The vertical dashed lines represent solar noon and sunset at the Millstone Hill radar site. The skewed dashed curves represent solar noon and sunset in the Blackstone radar field of view.

results from this statistical survey. Echoes with signal-to-noise ratio lower than $6 \mathrm{~dB}$ are ignored, only data collected on operating frequencies between 10 and $12 \mathrm{MHz}$ are considered, and days with more than $5 \mathrm{~h}$ of missing data are excluded. Months are selected to represent specific seasonal characteristics of the midlatitude ionosphere. Results from this statistical analysis are presented in Figure 6.

[13] To properly interpret ground scatter signatures in terms of ionospheric behavior, HF propagation in the ionosphere can be modeled using ray tracing [e.g., Hall et al., 1999]. We use the ray tracing code developed by Jones and Stephenson [1975] coupled with the latest International Reference Ionosphere (IRI) model [Bilitza, 2001]. F10.7 values for 2010 provided online by NOAA/NGDC are added to the IRI coefficients files, and the built-in IGRF model was completed with IGRF-11 coefficients to have a fully updated model. IDL wrappers have been developed to allow for easy comparison between SuperDARN data and ray tracing results: in the wrapper, a radar, operating frequency and beam number can be selected, then the IRI is executed to generate background electron densities over an altitude range of $500 \mathrm{~km}$ and an ground range of $2500 \mathrm{~km}$ along the selected radar beam, and finally the ray tracing code is executed using the IRI density profile as a background ionosphere. Results from two single runs of the coupled ray tracing-IRI model are presented in Figure 2. These single runs are repeated with the desired time resolution during a given time interval and collected to be presented on a rangetime plot as described for the radar analysis. The ground scatter power distribution is reconstructed by counting the number of rays reaching the ground per $45 \mathrm{~km}$ range gates. Note that absorption and variations in ground properties are ignored in this modeling of ground scatter. Ray tracing results designed to compare with radar statistical analysis 

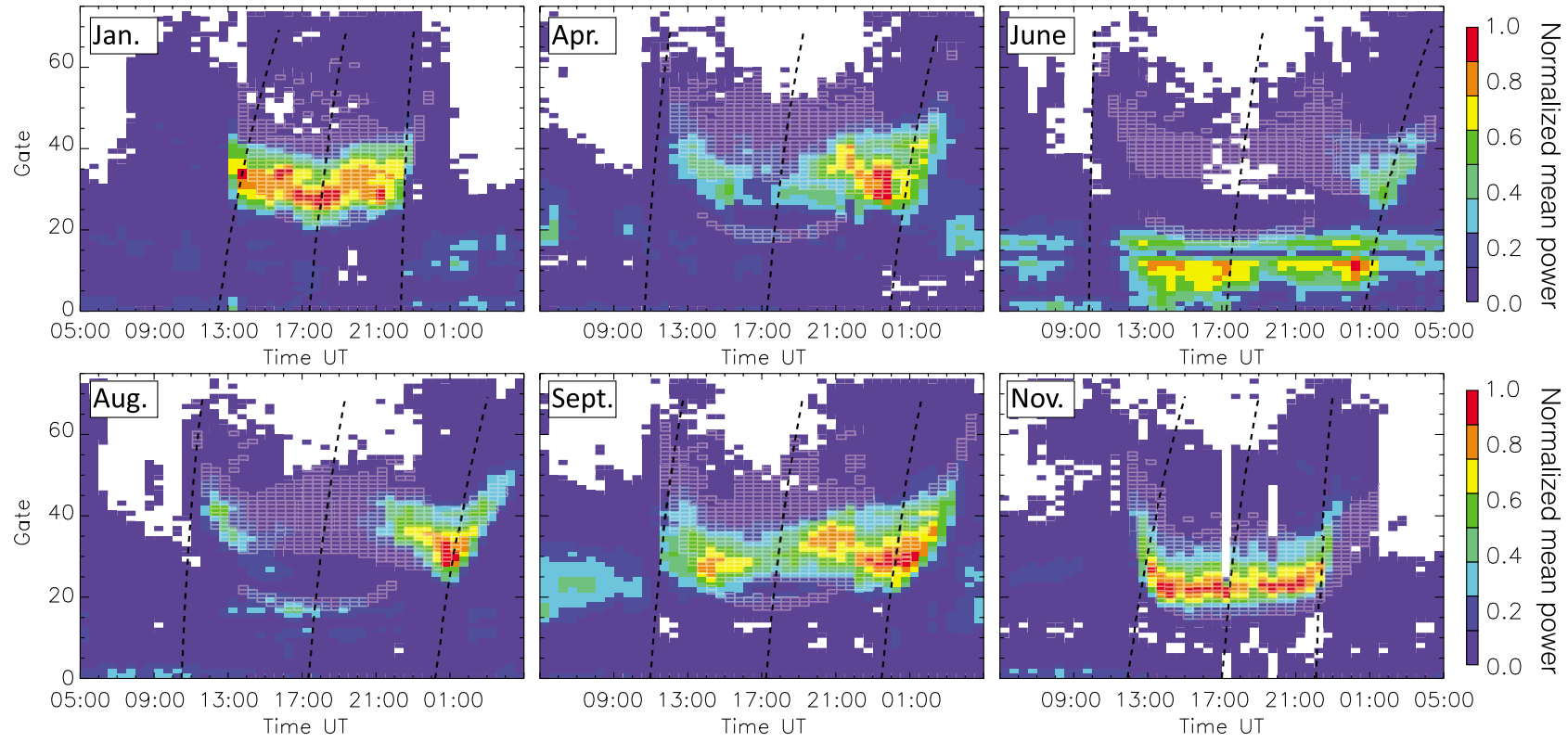

Figure 6. Daily variation of ground scatter observed by the Blackstone SuperDARN radar from statistical analysis of selected months of 2010. The light shaded areas correspond to modeled distribution of the ground scatter.

are presented in Figure 7 and overlaid on Figure 6 (light shaded areas).

\section{Results}

\subsection{Case Studies}

[14] It has already been shown in Figure 4 that the ground scatter distribution during a typical geomagnetically quiet summer day (Figure 4b) may present significant differences from the winter distribution (Figure $4 \mathrm{a}$ ). The first noticeable but not surprising difference is the time extent of the ground scatter being longer in summer (11:00 to 04:00 UT) than in winter (12:00 to 23:00 UT): this is simply due to longer Sun exposure during the summer, resulting in longer lasting high electron densities (sunrise, sunset and solar noon times are obtained from NOAA/ESRL and defined by the solar zenith angle on the ground). The second and more subtle difference is the emergence of a two-band structure in the ground scatter (especially visible in the afternoon in Figure $4 b$ ): this is due to the presence of the ionospheric $D$ region and lower
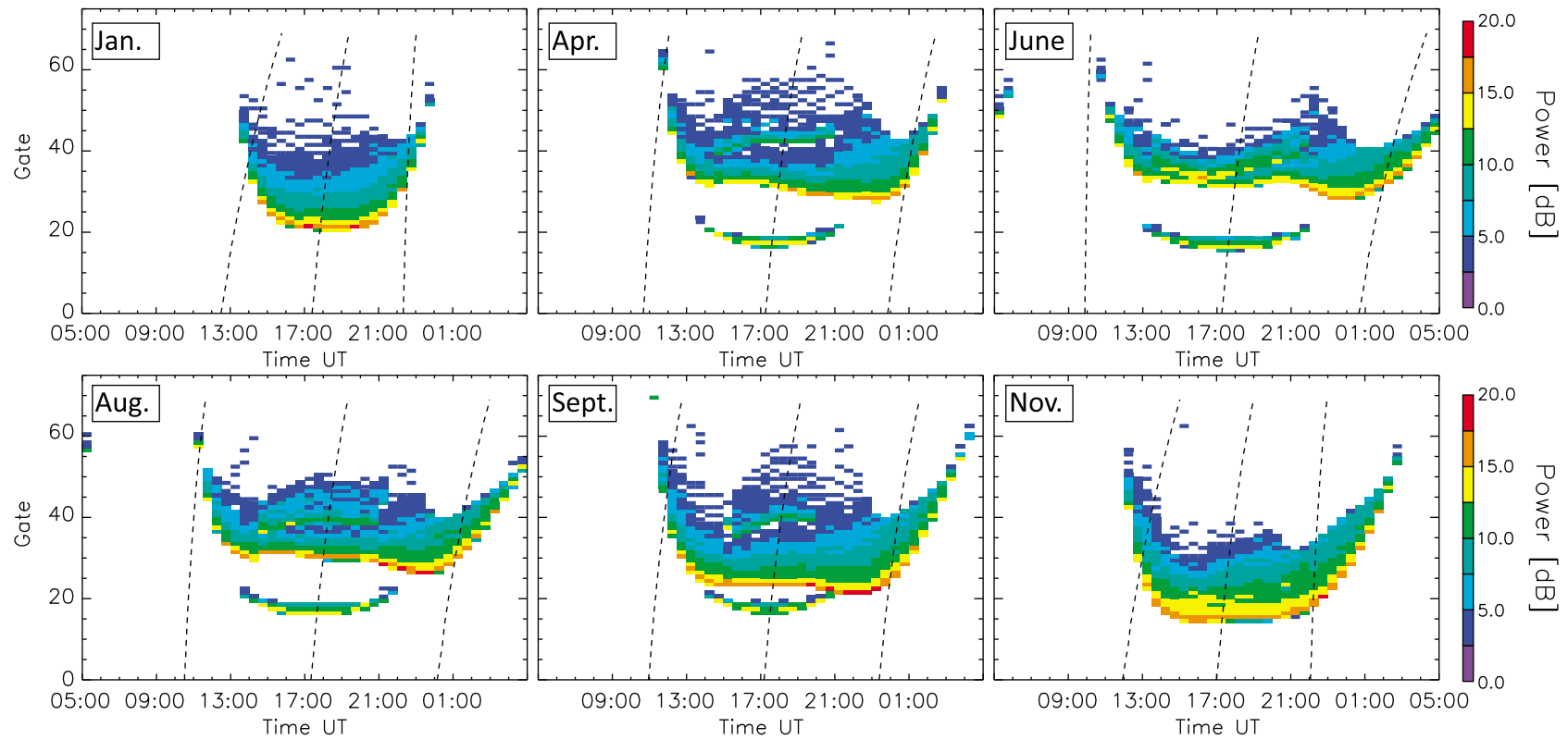

Figure 7. Ray tracing [Jones and Stephenson, 1975] coupled with IRI modeling of ground scatter as would be observed by beam 7 of the Blackstone radar in 2010. The plotted power distribution represents the number of rays in each $45 \mathrm{~km}$ range gate. 
$E$ region during the spring, summer and early fall months, which creates a second, closer skip distance. A third difference is the stronger daytime returned power in the winter: this is explained by both the absence of a lower $E$ region that would otherwise absorb and deflect part of the power reaching the $F$ region (which is responsible for the bulk of the ground scatter) and the winter anomaly which results in higher $F$ region densities in winter [Rishbeth and Garriott, 1969, p. 179-181]. The difference of greatest interest to this study is the enhancement in ground scatter that is observed to commence before sunset. The decay of the $E$ region before sunset will contribute to an enhancement in returned power from $F$ region-related ground scatter but would not account for the scatter moving closer in range, as seen in Figure 4b: absorption and deflection from the lower $E$ region would have a stronger effect on rays with low elevation angles (see Figure 2), which do not contribute to the $F$ region skip focusing distance.

[15] We have mentioned that previous observations from the Millstone Hill ISR revealed enhanced electron densities in the summer time evening midlatitude ionosphere. The location of the Millstone Hill ISR with respect to the Blackstone radar shown in Figure 3 suggests that a relation may exist between the enhancement in ground scatter observed at Blackstone and the electron density enhancement observed at Millstone Hill. To verify this relation, a geomagnetically quiet day has been found in the Madrigal database when the Millstone Hill ISR was running long enough during a summer evening to provide both daytime and nighttime electron densities. Data from this day, 13 August 2010, are presented in Figure 5 with both SuperDARN (Figure 5a) and Millstone Hill (Figure 5b) observations. In Figure 5a, the evening enhancement in ground scatter clearly appears around sunset. Electron densities from Millstone Hill show both $E$ and $F$ regions during daytime, accounting for the strong attenuation of daytime signal in SuperDARN data, as well as the dissipation of the $E$ region before sunset. The electron densities in the $2 \mathrm{~h}$ after sunset are notably higher than electron densities in the $F$ region at solar noon. This electron density enhancement presents a very good correlation with the ground scatter enhancement in SuperDARN data, confirming a relation between the two. Increased electron densities also lead to a shorter skip focusing distance as was evidenced by the ground scatter signature moving from gate $25(\sim 1305 \mathrm{~km})$ to gate $20(\sim 1080 \mathrm{~km})$ in Figure 5a.

\subsection{Statistical Results}

[16] We now conduct a statistical survey of ground scatter power distribution during given months of 2010. We chose specific months that represent significant changes in the ground scatter pattern. Results are presented in Figure 6 and can be described as follows. In January, the daily ground scatter distribution presents the expected pattern centered on solar noon. No $E$ region ground scatter trace is observed. Through the evening sector, the power distribution is somewhat irregular but is dominated by the expected retreat to larger ranges. In April, the daytime ground scatter power distribution is strongly attenuated, and the strongest power is observed around sunset. April shows the first occurrence of the midlatitude evening ground scatter enhancement. June daytime ground scatter is largely located at close ranges (before gate 20), which is typical of $E$ region activity. The $F$ region related ground scatter can only be observed around sunset, when $F$ region electron densities are enhanced and the $E$ region starts decaying. August exhibits a much reduced $E$ region activity compared to June, but the daytime power distribution of $F$ region related ground scatter is still largely absent: only around sunset can a strong ground scatter signature be observed. September presents a similar but not identical distribution as April. The daytime ground scatter is strongly attenuated but still presents a buildup around sunrise, and what seems like a retreat after solar noon followed by a new buildup before sunset, maximizing around sunset and finally retreating within 2-3 $\mathrm{h}$ after sunset. Finally, November returns us to the expected symmetrical variation about solar noon. Though not shown in the results of Figure 6, some cases of a weak evening enhancement in ground scatter are observed in October.

[17] The strong daytime attenuations observed from April through September are due to $E$ region effects on propagation. First, the stronger electron densities in the daytime $E$ region introduce a two-way absorption of the $F$ region related ground scatter signal. Second, these enhanced electron densities also contribute to the refraction of the HF rays and a separate $E$ region related ground scatter signature may appear, thus preventing part of the signal from ever reaching the $F$ region. This effect is enhanced in June because of the occurrence of sporadic $E$ during most of the day. The $E$ region typically decays rapidly around sunset as recombination at these altitudes is much faster than in the $F$ region. Consequently, it should be noted that the dissipation of the $E$ region alone will result in an increased returned power from $F$ region related ground scatter: this increase, however, is not strong enough to account for the observed enhancement, as will be verified in section 3.3. As previously stated, the dissipation of the $E$ region also cannot account for a range reduction in the ground scatter skip distance around sunset as is observed from April to September.

[18] The structure observed in September showing an initial recession of the ground scatter after solar noon suggests that the electron densities start decreasing and the $F$ region peak starts moving upward as would be expected and as illustrated in Figure 5b. The subsequent enhancement in ground scatter accompanied by shorter ranges suggest both that the electron densities are increasing and the $F$ region peak stops moving upward. The question remains as to whether the increase in electron densities should be attributed to a source of ionization other than solar radiation, to transport of ionized plasma from another sector of the ionosphere, or to a change in chemistry.

\subsection{Modeling Results}

[19] In order to compare ray tracing results to SuperDARN observations presented in Figure 6, an operating frequency of $11 \mathrm{MHz}$ for Blackstone's beam 7 is selected, and the code is executed for the 15th of each selected month, with a 30 min time resolution.The IRI model [Bilitza, 2001] is used to provide typical electron density profiles within the Blackstone field of view. Each 30 min window such as the ones presented in Figure 2 are collected and presented on a range-time plot. The simulated initial elevation angles range from $10^{\circ}$ to $35^{\circ}$ in accordance with expected antenna characteristics and Blackstone's interferometer array mea- 
surements. Ray tracing results are presented in Figure 7 as well as overlaid on Figure 6 (light shaded areas).

[20] We compare the modeling results of Figure 7 with the observational results summarized in Figure 6. January and November present the diurnal pattern symmetrical around solar noon, which is both expected and captured in statistical results. From April to September, a weak ground scatter signature appears around gate 20 that is clearly distinct from the bulk of the ground scatter. Finally, the main ground scatter signatures from April to September are characterized by closer and enhanced ground scatter around sunset.

[21] The weak ground scatter signature around gate 20 is related to the $E$ region bending part of the rays to the ground, further demonstrating the reason for weaker daily signals shown in radar observations. It should be noted that $E$ region signatures observed in June (Figure 6) were mainly due to sporadic $E$, which created an enhanced and disturbed $E$ region, thus explaining the difference between observations and modeling results in June. The occurrence of intense sporadic $E$ in June is not expressed by the IRI.

[22] June and August show a very pronounced evening enhancement that is clearly detached from the daytime ground scatter: it is especially noticeable in June that the ground scatter starts recessing before sunset, but increases again through sunset, as can also be seen in radar observations in September (Figure 6). It is apparent that the decay of the $E$ region is correlated to the beginning of the evening enhancement, which confirms that it contributes to the enhancement in $F$ region related ground scatter. However, as can be seen in Figure 2, the $F$ region skip focusing boundary is associated with higher elevation angles, while the $E$ region skip focusing boundary is determined by lower elevation angles; consequently, the decay of the $E$ region cannot account for the decrease in skip focusing distance shown in both observations and modeling.

[23] The comparison of observations and modeling demonstrates the blanking effect of the $E$ layer, and the statistical occurrence of $F$ region ground scatter presented in Figure 6 conforms well to the modeling results. Unlike the summertime midlatitude sporadic $E$, the evening anomaly is very well captured by the IRI. Since the IRI density profiles provide a statistical picture of the ionosphere under standard geomagnetically quiet conditions, it is safe to assume that the evening enhancement in ground scatter is the signature of recurring seasonal ionospheric behavior at midlatitudes over North America and not an isolated ionospheric perturbation.

\section{Discussion}

\subsection{Comparison With Recent Satellite Observations}

[24] Recent beacon tomography over Japan from Thampi et al. [2009] showed an enhancement in electron densities over latitudes greater than $33^{\circ} \mathrm{N}-34^{\circ} \mathrm{N}$ maximizing at $\sim 20: 00$ 21:00 LT. Another recent study from Lin et al. [2010] reports FORMOSAT-3/COSMIC observations showing a globally structured summer enhancement in electron densities. Both papers [Thampi et al., 2009; Lin et al., 2010] name this evening enhancement a midlatitude summer nighttime anomaly (MSNA) which is also meant to include the Weddell Sea anomaly (WSA). Results from both studies suggest that the equatorial ionization anomaly (EIA) may be involved in the generating mechanism of the observed enhancement in addition to previously suggested thermospheric neutral winds.

[25] A more comprehensive study by Liu et al. [2010] using data from the CHAMP satellite demonstrated that the northeastern American sector is part of a well defined midlatitude summer phase reversal of the diurnal cycle: Figure 1 of Liu et al. [2010] shows that the region matching the SuperDARN and Millstone Hill observations labeled Northern Atlantic (NA), together with sectors of Eastern Asia (EA) and South Pacific (SP), present depleted daytime electron densities and enhanced evening/nighttime electron densities in the midlatitude $F$ region.

[26] Assuming a constant eastward and equatorward wind at night and a westward and poleward wind during the day, Liu et al. [2010] suggested that the combined effects of neutral winds and the geomagnetic configuration could potentially explain both the daytime depletion and the nighttime enhancement in $F$ region electron densities. Additional constraints may apply to the neutral wind as altitude will affect the neutral-ion collision frequency, thus limiting the range of altitudes where the neutral winds can efficiently push the ionosphere up or down [e.g., Kelley, 2009 , pp. 242-243]. It should also be noted that horizontal wind directions under $150 \mathrm{~km}$ altitude can be reversed compared to higher altitudes.

[27] Liu et al. [2010] also suggests that the seasonal variation of the thermal contraction of the ionosphere may significantly contribute to the seasonal variation of the diurnal phase reversal. More modeling would be needed to verify this hypothesis, but earlier work by Eccles and Burge [1973] concluded that the thermal contraction of the ionosphere only contributed to modifying the structure of the topside ionosphere such that at high altitudes above the $F$ region the evening enhancement occurs earlier than it does at the $F$ region peak.

[28] A very recent study by Burns et al. [2011] used global maps of COSMIC $\mathrm{NmF}_{2}$ and $\mathrm{hmF}_{2}$ data for two months either side of the June and December solstices for 2006-2008, as well as a trace of the ground terminator and its magnetic conjugate. The authors conclude that if there is sufficient time between the crossing of the conjugate terminator first and the real terminator second at midlatitude, an evening enhancement is observed near the real terminator. It should be noted that the distance between the terminator and its conjugate is directly related to field lines declination, which could impact neutral wind lifting efficiency as detailed in section 4.2. Additionally, Burns et al. [2011] suggest that the increase in $\mathrm{hmF}_{2}$ does not occur at the same time as the increase in $\mathrm{NmF}_{2}$ as would be expected if neutral winds were responsible for the enhancement. This delay between the lifting of the ionosphere and the electron density enhancement does not appear clearly in our data or in the figures of Burns et al. [2011]: one could also argue that recombination could start, lifting the $F$ layer peak without resulting in a density enhancement, soon followed by a wind driven additional lift which would stall recombination by pushing ions to higher altitudes, thus producing enhanced $F$ region densities. Burns et al. [2011] suggest that polarization electric fields could drive an upward poleward drift that would transport ions associated with the equatorial anomaly. Burns et al. [2011] points out that such a transport 
IRI Dec. 21, 2010: 22LT

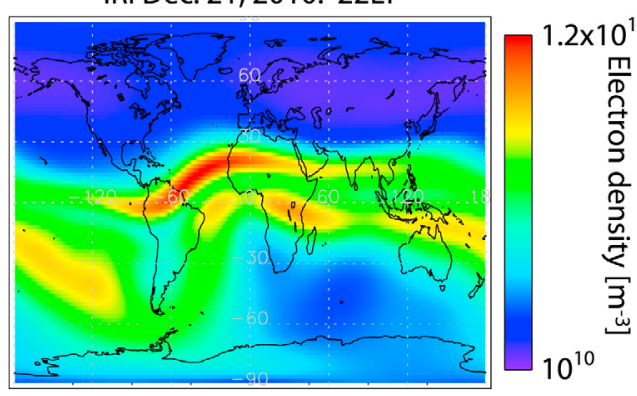

IRI Dec. 21, 2010: 12LT

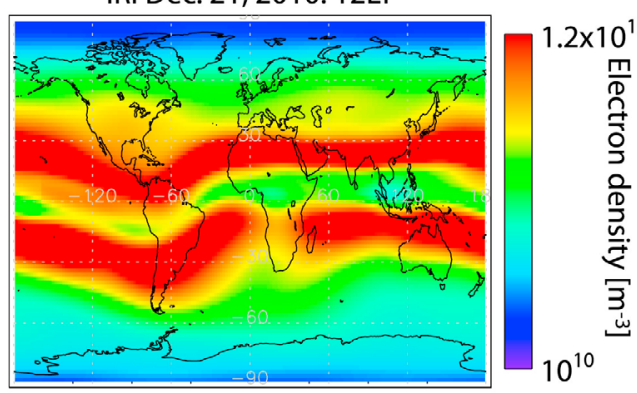

IRI June 21, 2010: 22LT

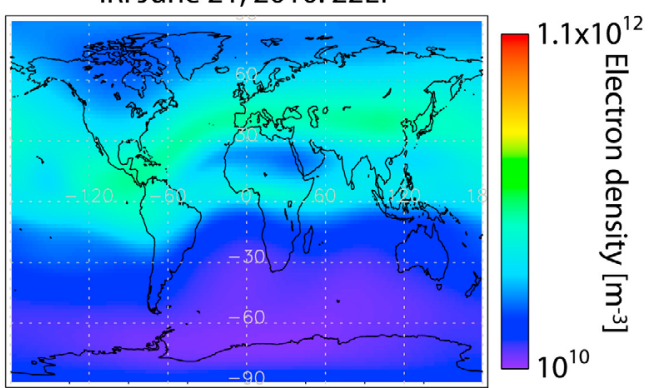

IRI June 21, 2010: 12LT
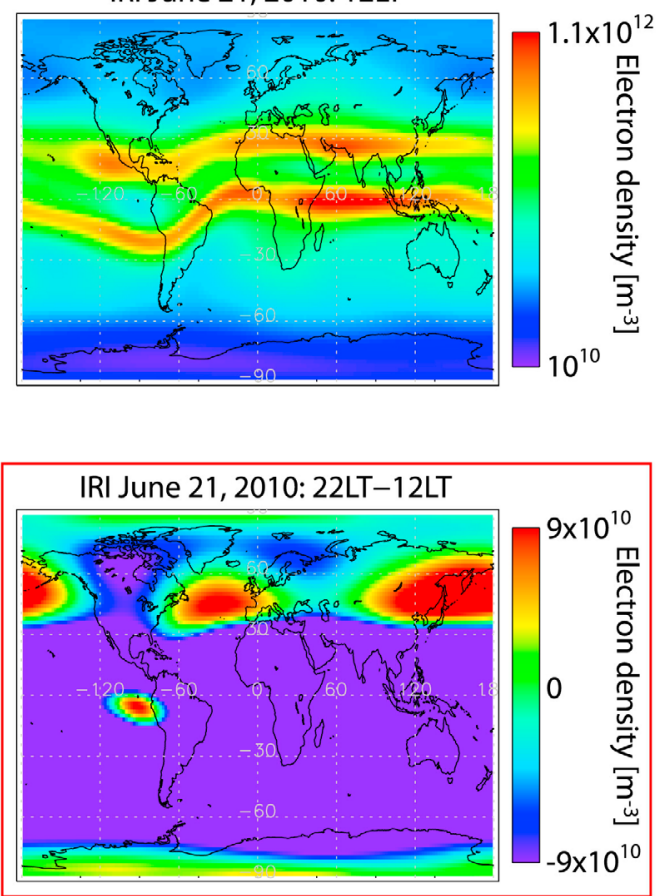

Figure 8. Global distribution of electron densities at $300 \mathrm{~km}$ altitude obtained with the IRI model [Bilitza, 2001]. The two bottom maps are generated by subtracting electron densities at 12:00 LT from those at 22:00 LT to represent the intensity and coverage of the summer evening enhancement in both hemispheres. In the bottom maps, positive values are indicative of enhanced evening density, while negative values represent the expected evening reduction in electron density with respect to noon.

would require ion drift velocities higher than what is usually observed and that such a mechanism needs further quantitative investigation.

[29] Two mechanisms have now been identified to potentially explain the evening enhancement: thermospheric neutral winds [Eccles and Burge, 1973; Lin et al., 2010], and polarization electric fields coupled with interhemispheric conjugacy [Burns et al., 2011].

\subsection{Global Model Results}

[30] Having demonstrated the temporal evolution of the evening enhancement with both radar data (Figures 5 and 6) and ray tracing results (Figure 7), we now wish to investigate the global spatial characteristics of this phenomenon. The significance of the summer evening enhancement is such that it is safe to assume it should appear in a global empirical model such as the IRI [Bilitza, 2001]. Figure 8 shows a similar figure to the one obtained by Liu et al. [2010]: using IRI, electron densities at $300 \mathrm{~km}$ altitude are obtained for the summer and winter solstices. The panel outlined by a red box in Figure 8 (bottom) shows the difference in electron densities between 20:00 and 12:00 LT, which clearly shows two sectors of evening enhancement in the Northern Hemisphere similar to those described by Liu et al. [2010]. It can be seen that SuperDARN measurements of the evening enhancement over northeastern America are at the edge of the active sector. It should be expected that the extended SuperDARN midlatitude chain will be able to observe this longitudinal variation.

[31] Using geomagnetic field configuration from the IGRF model combined with horizontal wind from the HWM07 model [Drob et al., 2008] and the equation giving the effective vertical wind as a function of magnetic dip and declination angles [Titheridge, 1995, equation 2], a map of 
HWM07 + IGRF: 21/Dec./2010 - 20LT - z=150 km
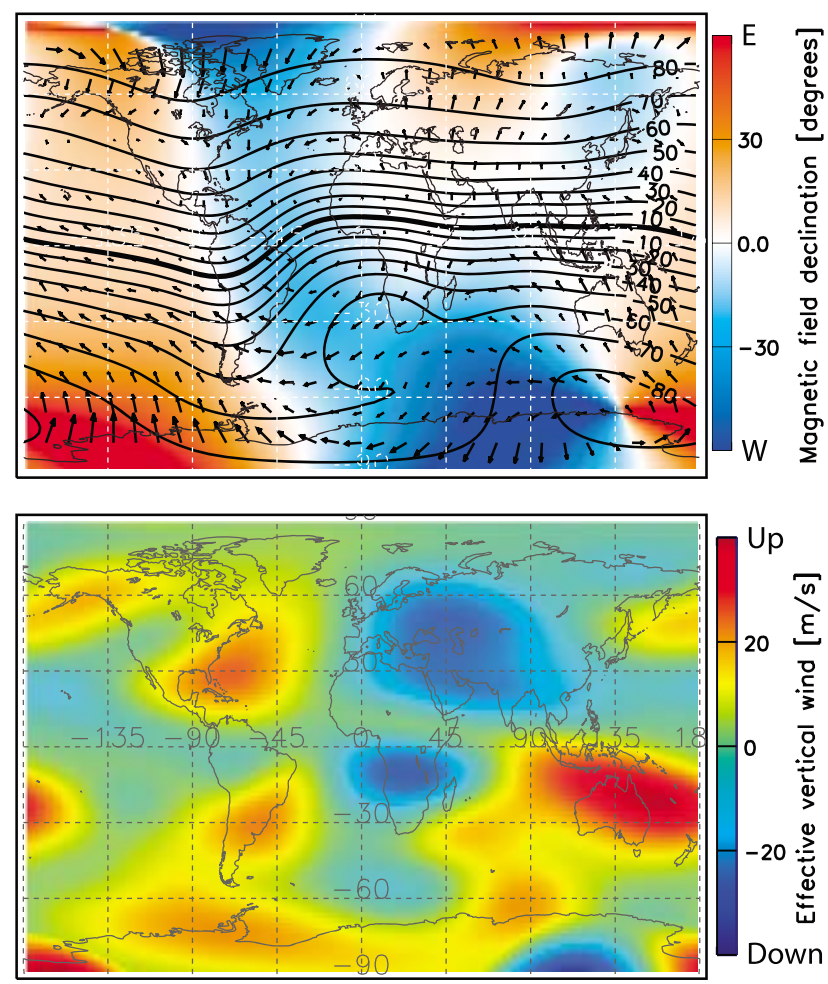

HWM07 + IGRF: 21/Jun./2010 - 20LT - z=150 km
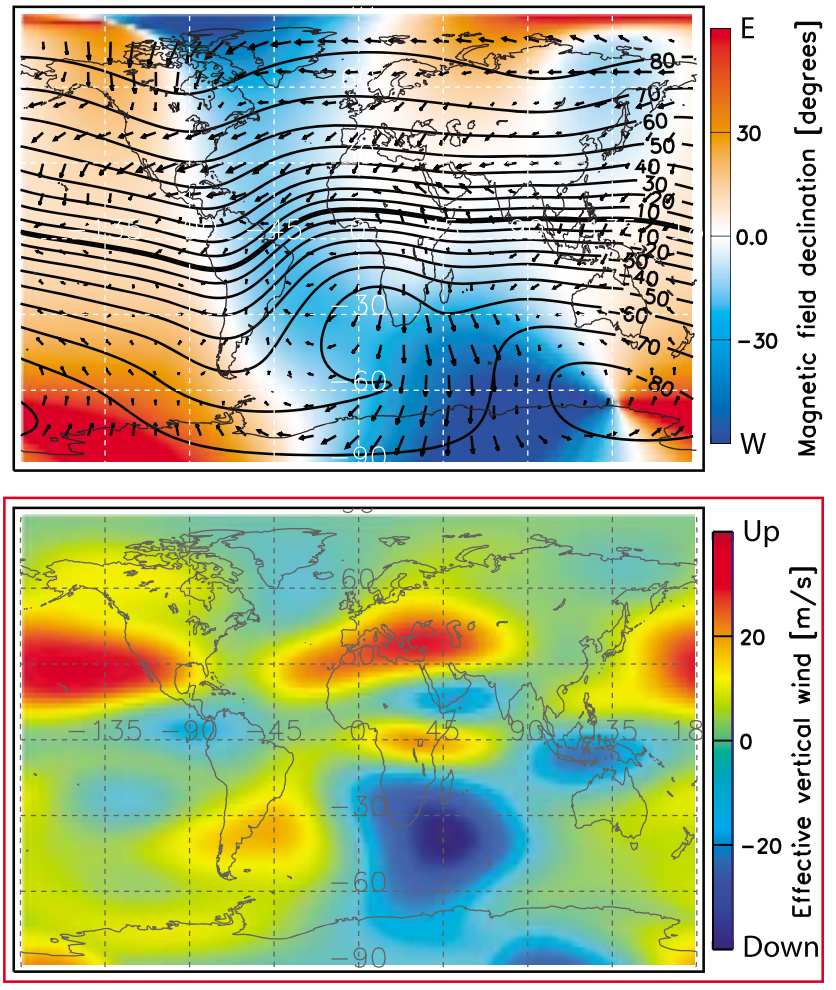

Figure 9. (top) Vector wind velocities from the HWM07 model [Drob et al., 2008] at 20:00 LT at an altitude of $150 \mathrm{~km}$ for the (right) summer and (left) winter solstices, plotted over magnetic dip isoclinic line and magnetic field line declination from the IGRF model. (bottom) Effective vertical winds computed using model results presented in Figure 9 (top) [Titheridge, 1995, equation 2].

effective vertical winds is presented in Figure 9 for the evenings of the summer and winter solstices. Figure 9 (top) shows the input parameters for the effective vertical wind computation: wind vectors at $150 \mathrm{~km}$ altitude and 20:00 LT are represented alongside magnetic dip angle isoclinic and magnetic field declination (positive eastward, negative westward). The altitude was chosen to represent a first-order approximation of the mean altitude of a source layer to the evening enhancement in electron density. Figure 9 (bottom) shows the combination of horizontal winds at $150 \mathrm{~km}$ altitude with magnetic dip and declination into an effective vertical wind at $150 \mathrm{~km}$ altitude at 20:00 LT. The panel outlined in red is to be compared with the outlined panel in Figure 8. Thermospheric winds at $150 \mathrm{~km}$ in the Northern Hemisphere result in efficient vertical winds with a longitudinal distribution very similar, though misaligned, to the electron density evening enhancement depicted in both IRI results (Figure 8) and satellite observations: strong vertical winds can be observed over two regions of the Northern Hemisphere during the summer that are not reproduced in the winter. Finally, it is important to notice that there does not seem to be strong effective upward winds at this given altitude and local time during the winter solstice (Figure 9, left) that could account for the Weddell Sea anomaly in the Southern Hemisphere. However, it can be reasonably assumed that the HWM07 does not perform as well in the Southern Hemisphere as it does in the Northern. Limited data from the Southern Hemisphere results in less reliable empirical predictions: therefore, model results for this hemisphere should not be interpreted as contradicting the influence of winds in the WSA.

[32] In interpreting Figure 9, one has to take into account that the vertical wind influence covers a wide altitude range and that this influence is mainly regulated by the ion-neutral collision frequency, which decreases with altitude. Considering the fixed altitude and time results presented in Figure 9, the strong effective vertical winds of $20-40 \mathrm{~m} / \mathrm{s}$ at $150 \mathrm{~km}$ altitude modeled in the Northern Hemisphere would result in enhanced $F$ region peak densities $(\sim 300 \mathrm{~km})$ about $1-2 \mathrm{~h}$ later, which may account for the displacement of the longitudinal structure seen in comparing Figures 8 and 9. For example, the vertical wind enhancement that is centered on the Mediterranean in Figure 9 becomes responsible for the evening enhancement seen centered on the North Atlantic Ocean in Figure 8. More modeling is needed to evaluate the altitude dependency of the coupling between thermospheric neutral winds and the lower $F$ region ionosphere, but the initial results presented here are very encouraging.

\section{Conclusion}

[33] The recent installation of SuperDARN radars at midlatitude reveals the presence of an evening enhancement in ground scatter characterized by (1) a higher signalto-noise ratio around sunset, (2) a reduction of the ground scatter range from the radar, and (3) occurrences on most 
geomagnetically quiet days from April to September. Modeling results from ray tracing coupled with the IRI shows a very good correlation with observations, suggesting the enhancement is related to a well defined statistically significant ionospheric structure.

[34] A single event was found providing joint observation of the ionosphere on a geomagnetically quiet day by both the Blackstone $\left(37.10^{\circ} \mathrm{N}, 282.05^{\circ} \mathrm{E}\right)$ SuperDARN radar and the Millstone Hill incoherent scatter radar $\left(42.6^{\circ} \mathrm{N}\right.$, $\left.288.5^{\circ} \mathrm{E}\right)$. On this event, a very good correlation appears between the ground scatter enhancement and electron density enhancement in the $F$ region over Millstone Hill. This correlation suggests that SuperDARN observations of a midlatitude summer evening enhancement in ground scatter is most likely related to previous reports of a summer evening enhancement in electron densities over Millstone Hill. More joint observations with both SuperDARN midlatitude radars and the Millstone Hill ISR could provide a good time resolution of the development of the evening enhancement, as well as a better understanding of the dayto-day variability of the enhancement and the role of neutral winds in its development.

[35] Recent satellite observations reporting a globally structured evening enhancement in electron densities in the $F$ region during Northern Hemisphere summers shows promising results and is most likely related to the enhancements observed by both SuperDARN and Millstone Hill. Global electron density maps generated using the IRI model exhibit a very good correlation with satellite observations of the evening enhancement and further verify that SuperDARN observations of the evening enhancement are related to the satellite observations of electron densities in the $F$ region. Additionally, results from the HWM07 model supports previous studies that emphasized the importance of the neutral winds in generating the observed evening enhancement.

[36] In this paper we report on the first observation of the evening enhancement by the new midlatitude SuperDARN radars, and we are able to relate SuperDARN results to previous ISR and satellite observations. We also show that the evening enhancement is very well represented by the IRI model. Finally, results from the HWM07 model suggest that the seasonal variation of the evening enhancement is most likely related to the seasonal variation of thermospheric neutral winds combined with geomagnetic field configuration. Further investigation is needed to quantify the relative importance of the three currently identified factors of the evening enhancement: (1) thermospheric neutral winds, (2) the geomagnetic field configuration, and (3) polarization electric fields coupled with interhemispheric conjugacy. More information on the day-to-day variability and the longitudinal structure of the evening enhancement would be needed to establish a proper correlation with the three previously mentioned factors: the recent extension of the SuperDARN midlatitude chain is expected to consolidate that information.

[37] Acknowledgments. We are grateful to Anthea J. Coster and Shun-Rong Zhang from the MIT Haystack Observatory for providing valuable references on the evening enhancement observed by the Millstone Hill ISR. The Madrigal database is assembled and maintained by members of MIT haystack Observatory Atmospheric Science Group. Radar observa- tions and analysis at Millstone Hill for the time period presented here are supported under Cooperative Agreement ATM-0733510 with the Massachusetts Institute of Technology by the U.S. National Science Foundation under the Geospace Facilities program. M. Lester is supported by STFC grant ST/H002480/1. This research was supported by NSF AGS0946900 to Virginia Tech.

[38] Robert Lysak thanks the reviewers for their assistance in evaluating this paper.

\section{References}

Bilitza, D. (2001), International Reference Ionosphere 2000, Radio Sci. $36(2), 261-275$

Blanchard, G. T., S. Sundeen, and K. B. Baker (2009), Probabilistic identification of high-frequency radar backscatter from the ground and ionosphere based on spectral characteristics, Radio Sci., 44, RS5012, doi:10.1029/2009RS004141.

Bristow, W. A., R. A. Greenwald, and J. P. Villain (1996), On the seasonal dependence of medium-scale atmospheric gravity waves in the upper atmosphere at high latitudes, J. Geophys. Res., 101, 15,685-15,699.

Budden, K. G. (1966), Radio Waves in the Ionosphere, Cambridge Univ. Press, Cambridge, U. K.

Burns, A. G., S. C. Solomon, W. Wang, G. Jee, C. H. Lin, C. Rocken, and Y. H. Kuo (2011), The summer evening anomaly and conjugate effects, J. Geophys. Res., 116, A01311, doi:10.1029/2010JA015648.

Chisham, G., et al. (2007), A decade of the Super Dual Auroral Radar Network (SuperDARN): Scientific achievements, new techniques and future directions, Surv. Geophys., 28, 33-109.

Drob, D. P., et al. (2008), An empirical model of the Earth's horizontal wind fields: HWM07, J. Geophys. Res., 113, A12304, doi:10.1029/ 2008JA013668.

Eccles, D., and J. D. Burge (1973), The behaviour of the upper ionosphere over North America at sunset, J. Atmos. Sol. Terr. Phys., 35, 1927-1934.

Evans, J. V. (1965), Cause of the mid-latitude evening increase in $f_{0} F_{2}$, J. Geophys. Res., 70, 1175-1185.

Hall, G. E., J. W. MacDougall, J. F. Cecile, D. R. Moorcroft, and J. P. St-Maurice (1999), Finding gravity wave source positions using the Super Dual Auroral Radar Network, J. Geophys. Res., 104, 67-78.

Hughes, J. M., W. A. Bristow, R. A. Greenwald, and R. J. Barnes (2002), Determining characteristics of HF communications links using SuperDARN, Ann. Geophys., 20, 1023-1030.

Jones, R. M., and J. J. Stephenson (1975), A versatile three-dimensional ray tracing computer program for radio waves in the ionosphere, OT Rep. 75-76.PB2488567, U.S. Dept. of Comm., Washington, D. C.

Kelley, M. C. (2009), The Earth's Ionosphere, Plasma Physics and Electrodynamics, 2nd ed., Elsevier, Amsterdam.

Lei, J., L. Liu, W. Wan, and S.-R. Zhang (2005), Variations of electron density based on long-term incoherent scatter radar and ionosonde measurements over Millstone Hill, Radio Sci., 40, RS2008, doi:10.1029/ 2004RS003106

Lin, C. H., C. H. Liu, J. Y. Liu, C. H. Chen, A. G. Burns, and W. Wang (2010), Midlatitude summer nighttime anomaly of the ionospheric electron density observed by FORMOSAT-3/COSMIC, J. Geophys. Res., 115, A03308, doi:10.1029/2009JA014084.

Liu, H., S. V. Thampi, and M. Yamamoto (2010), Phase reversal of the diurnal cycle in the midlatitude ionosphere, J. Geophys. Res., 115, A01305, doi:10.1029/2009JA014689.

Milan, S. E., T. K. Yeoman, M. Lester, E. C. Thomas, and T. B. Jones (1997), Initial backscatter occurrence statistics from the cutlass HF radars, Ann. Geophys., 15, 703-718.

Norman, R., and P. Dyson (2006), HF radar backscatter inversion technique, Radio Sci., 41, RS4010, doi:10.1029/2005RS003355.

Ponomarenko, P., F. Menk, C. Waters, and M. Sciffer (2005), Pc3-4 ULF waves observed by the SuperDARN TIGER radar, Ann. Geophys., 23, 1271-1280.

Ponomarenko, P. V., J. P. S. Maurice, G. C. Hussey, and A. V. Koustov (2010), HF ground scatter from the polar cap: Ionospheric propagation and ground surface effects, J. Geophys. Res., 115, A10310, doi:10.1029/2010JA015828.

Ribeiro, A. J., J. M. Ruohoniemi, J. B. H. Baker, L. B. N. Clausen, and S. de Larquier (2011), A new approach to identifying ionospheric backscatter in mid-latitude SuperDARN data, Radio Sci., 46, RS4011, doi:10.1029/2011RS004676.

Rishbeth, H., and O. K. Garriott (1969), Introduction to Ionospheric Physics, Int. Geophys. Ser., vol. 14, Academic, New York.

Ruohoniemi, J. M., and K. B. Baker (1998), Large-scale imaging of highlatitude convection with Super Dual Auroral Radar Network HF radar observations, J. Geophys. Res., 103, 20,797-20,811. 
Samson, J. C., R. A. Greenwald, J. M. Ruohoniemi, and K. B. Baker (1989), High-frequency radar observations of atmospheric gravity-waves in the high-latitude ionosphere, Geophys. Res. Lett., 16(8), 875-878.

Schunk, R. W., and A. F. Nagy (2009), Ionospheres: Physics, Plasma Physics, and Chemistry, 2nd ed., Cambridge Univ. Press, Cambridge, U. K.

Thampi, S. V., C. Lin, H. Liu, and M. Yamamoto (2009), First tomographic observations of the midlatitude summer nighttime anomaly over Japan, J. Geophys. Res., 114, A10318, doi:10.1029/2009JA014439.
Titheridge, J. E. (1995), Winds in the ionosphere: A review, J. Atmos. Sol. Terr. Phys., 57(14), 1681-1714.

J. B. H. Baker, S. de Larquier, N. Ravindran Varrier, and J. M. Ruohoniemi, SuperDARN HF Radar Group, Virginia Polytechnic Institute and State University, Suite 2019, 1991 Kraft Dr., Blacksburg, VA 24060, USA. (sdelarquier@vt.edu)

M. Lester, Department of Physics and Astronomy, University of Leicester, Leicester LE1 7RH, UK. 